\title{
Comparative Study :The Incidence of Catheter Associated Urinary Tract Infection (CAUTI) between Foley and Silicon Catheter.
}

\author{
Mohamed., M., G., Mekkawy., M., M., Ahmed., A., M .,A., Abdellatif., A., R \& yousif .,L., M. \\ Medical-Surgical Nursing, Faculty of Nursing, Sohag University, Medical-Surgical Nursing, Faculty of Nursing, \\ Assiut University, Faculty of Medicine, Sohag University
}

\begin{abstract}
:
The aim to compare the incidence of catheter-associated urinary tract infection (CAUTI) between foley and silicone catheter. Descriptive exploratory design was utilized in this study. The study was conducted in the Urology department at Sohag University Hospital. A convenient sample of 120 patients male and female was included in this study. Tools were used for data collection, Tool (1) patient assessment sheet and Tool (2) post catheterization problems evaluation sheet. Results findings regarding to patients' characteristics revealed that, two third of patients (60.0\%) aged between 31-50 years. As regard the length of hospital stay, half of foley catheterized patients (50.0\%) admitting between 4-6 days, while (43.3\%) of silicon catheterized patients admitting between 7-9 days. As regard the urine culture result, that more than three quarters of foley catheterized patients $(76.7 \%)$ were positive culture result and two third of silicon catheterized patients $(60.0 \%)$ were positive culture result. Conclusion significant relation was present between incidence of urinary tract infection and types of catheter, length of hospital $(\mathrm{P}=0.03$ and $\mathrm{P}=0.001$ respectively), while non-significant relation was present between incidence of urinary tract infection and patients sex. Recommendations use a sterile procedure for catheter insertion to reduce catheter associated infection. Increasing alert of health care staff about infection control and measure to prevent CAUTI through work shop, posters and health education.
\end{abstract}

\section{Key Words: Catheter-associated urinary tract infection, correlation, Foley catheter, Silicon catheter, Incidence.}

\section{Introduction:}

Urinary tract infection (UTI) is defined as significant bacteriuria in the presence of a constellation of symptoms such as dysuria, increased urinary frequency and urgency, suprapubic discomfort and costovertebral angle tenderness. It is a common cause of infections, particularly among young, sexually active women; an estimated 1 in 3 women will develop a urinary tract infection before the age of 24 years (Tenke \&Kovacs,2008) .

In the hospitalized patient, urinary tract infection may account for close to $50 \%$ of hospital-acquired infections and are a major cause of gram negative bacteremia and mortality. They account for more than 7 million visits to physicians' offices and necessitate or complicate over 1 million office visits and 1 million emergency department visits, resulting in 100,000 hospitalizations annually. They account for $1.2 \%$ of all office visits by women and $0.6 \%$ of all office visits by men (Kunin, 2006).

Between $15 \%$ and $25 \%$ of hospitalized patients, may have a urinary catheter in place at some stage during their stay. Most are in situ for only a short time (between 2 and 10 days) but many patients both in hospital and in the community remain catheterized for long periods (Bjerklund \&Cek 2007) .

In catheterized patients, the risk of developing a catheter-associated urinary tract infection (CAUTI) increases between $3 \%$ and $6 \%$ per day. When the catheter is in situ for longer than a week, approximately $50 \%$ of catheterized patients is at serious risk of contracting an infection (Schumm\& Lam, 2009).

Catheter-associated bacteriuria and asymptomatic bacteriuria (CA-ASB) is the most common health care-associated infection worldwide and is a result of the widespread use of urinary catheterization, much of which is inappropriate, in hospitals and long term care facilities (LTCFs). Considerable personnel time and other costs are expended by health care institutions to reduce the rate of CAUTI (Thomas \&Suzanne, 2010).

CAUTI can lead to such complications as cystitis, pyelonephritis, gram negative bacteremia, prostatitis, epididymitis, and orchitis in males and, less commonly, endocarditis, vertebral osteomyelitis, septic arthritis, endophthalmitis, and meningitis in all patients. Complications associated with CAUTI cause discomfort to the patient, prolonged hospital stay, and increased cost and mortality. Each year, more than 13,000 deaths are associated with UTIs (Dudeck \&Hora , 2011).

To minimize the potential for introduction of microorganisms into the bladder, urinary catheters should only be inserted by properly trained nurse. Hand hygiene is the most important means of preventing 
infection and should be performed immediately before and after insertion or any manipulation of the catheter device or site. Indwelling catheters should be inserted using aseptic technique and sterile equipment. Cleansing the perineal area to decrease bacteria in the surrounding area is highly recommended (Gould \& Umscheid, 2010).

During the catheterization procedure, efforts should also be made to minimize pain and trauma. These efforts include using an appropriate size catheter, lubricating the catheter thoroughly, and inserting the catheter far enough into the bladder to prevent trauma to the urethral tissues with the inflation of the retention balloon. The indwelling catheter should be secured to the thigh or abdomen after insertion to prevent movement and the exertion of excessive force on the bladder neck (Hooton \&Bradley, 2010).

\section{Aim of the study:}

To compare the incidence of catheter-associated urinary tract infection (CAUTI) between Foley and silicone catheter in patients undergoing urinary catheterization in urology department.

Patient and methods

\section{Research design}

A descriptive exploratory design was utilized to fulfil the aim of this study.

\section{Setting:}

The study was conducted in the Urology department at Sohag University Hospital.

\section{Sample:}

A convenience sample of all available patients in urology department, sample of (120) patients male and female aged between (18-65) years who are admitted to urology department and undergoing urinary catheterization within 7-10 days. The patients will be divided to two groups as the following: male groups: composed of (60) male patients divided equally to two groups one group with foley catheter and another group with silicon catheter, and female groups: composed of (60) female patients divided equally to two groups one group with foley catheter and another group with silicon catheter.

Exclusion criteria: Patient with recent history of UTI, recent (with in 3 weeks) use of a urinary catheter, previous radiation therapy over the lower pelvis, cognitive impairment, stones in urinary bladder and patient with diabetes mellitus.

\section{Tools:}

Tool 1: patient assessment sheet; it includes three parts:

Part I: Socio demographic data:

This tool collected the necessary data about study subject. It was included of 9 questions covering the following; patient's name, code, age, gender, phone number, level of education, marital status, occupation, and type of group.

Part II: Patient medical data:

It was included 14 questions covering the following items; date of admission, length of stay, date of discharge ,use of antibiotic, type of antibiotic, period of catheter insertion, catheter size, catheter type, catheter lumen, indications for catheterization, characteristics of urine output, chronic illnesses, Patient habits and risk factors for infection.

Part III: Laboratory investigation; it include, urine culture test and sensitive antibiotics.

Tool 2: patient evaluation sheet; this tool identifies post urinary catheterization problems. This tool was developed in (2011) (Stenzelius \& Persson ,2011) to assess post catheterization problems. Scoring system: Each item was categorized and scored into either: Not, at all (1),Yes, a little (2), Yes, much (3) ,Yes, very much (4). It includes two parts; Part I: Local manifestations of infection; it was included 11 questions covering the following items:

A painful burning sensation, uneasy feeling in urethra , dragging feeling, burning sensation, strong smell urine, discomfort or pressure in the lower abdomen , difficulties holding the catheter in place, cramping in the pelvic area or back, cloudy urine, urge sensation and urine contains blood.

Part II: General manifestations of infection; it was included 2 questions covering the following items: Fever and confusion.

\section{Ethical approval:}

Inform consent has been taken after the researcher explains to patients about purpose of the study. Patients were advised of their right to withdraw from the study at any point. Patient's names were coded for data entry so that their names could not be identified. Patients' agreement for voluntary participation was obtained and the purpose and nature of the study was explained.

A pilot study: Carried out in mid January 2012 to evaluate the clarity and applicability of the study tools on groups of 12 patients (10\%) of sample 3 patients for each group. The purpose of the pilot study was to detect any particular problem in the statements clarity, feasibility, and applicability of the tool. The data obtained from the pilot study wear analyzed, no change was done in the assessment sheet, so the 12 patients selected for the pilot study were included in the main study.

Data were collected at Urology department at Sohag university hospital during the period from February 2012 to June 2012. The tools were all filled through interviewing. The purpose of the study was explained to the patients prior to answering the questions. The 
study was carried out during morning and after noon shifts for all available patients.

The participating patients, were interviewed three times, the first interview was done to take assessment sheet immediately after patient admission to urology unit and insert urinary catheter. The second was done during remove of urinary catheter to take urine sample for urine culture then labelled by patient name and date then sent to the laboratory in sterile containers. The third interview was done in outpatient clinic when the patients come to follow up after discharge by about one week then researcher interviewing patient to ask about post urinary catheterization problems "evaluation sheet". Data collected and analyzed by computer program SPSS" ver. 16" Chicago. USA Data expressed as number and Percentage, using Likelihood ratio to determine significant for groups.

$\mathrm{P}>0.05$ non- significant.

$\mathrm{P} \leq 0.05$ significant.

$\mathrm{P} \leq 0.001$ highly significant

\section{Results:}

Table (1): Frequency distribution of the study sample according to socio-demographic characteristics:

\begin{tabular}{|c|c|c|c|c|c|c|c|c|}
\hline \multirow{3}{*}{ Variables } & \multicolumn{4}{|c|}{ Foley catheters } & \multicolumn{4}{|c|}{ Silicon catheters } \\
\hline & \multicolumn{2}{|c|}{ Male $($ No. $=30)$} & \multicolumn{2}{|c|}{ Female(No.=30) } & \multicolumn{2}{|c|}{ Male(No.=30) } & \multicolumn{2}{|c|}{ Female(No. $=30)$} \\
\hline & NO. & $\%$ & NO. & $\%$ & NO. & $\%$ & NO. & $\%$ \\
\hline $\begin{array}{ccc}\text { Age: } & & \\
\bullet & 18-30 & \text { years } \\
\bullet & 31-50 & \text { years } \\
\bullet & 51-65 & \text { years } \\
\end{array}$ & $\begin{array}{c}8 \\
18 \\
4 \\
\end{array}$ & $\begin{array}{l}26.7 \\
60.0 \\
13.3\end{array}$ & $\begin{array}{c}8 \\
17 \\
5\end{array}$ & $\begin{array}{c}26.7 \\
56.7 \\
16.7 \\
\end{array}$ & $\begin{array}{c}7 \\
18 \\
5\end{array}$ & $\begin{array}{l}23.3 \\
60.0 \\
16.7\end{array}$ & $\begin{array}{l}10 \\
10 \\
10\end{array}$ & $\begin{array}{l}33.3 \\
33.3 \\
33.3 \\
\end{array}$ \\
\hline $\begin{array}{cl}\text { Level of education: } \\
\text { - } & \text { Illiterate } \\
\text { - } & \text { Read \& write } \\
\text { - } & \text { Basic education } \\
\text { - } & \text { University } \\
\end{array}$ & $\begin{array}{c}7 \\
10 \\
10 \\
3\end{array}$ & $\begin{array}{l}23.3 \\
33.3 \\
33.3 \\
10.0 \\
\end{array}$ & $\begin{array}{c}10 \\
10 \\
8 \\
2 \\
\end{array}$ & $\begin{array}{c}33.3 \\
33.3 \\
26.7 \\
6.7 \\
\end{array}$ & $\begin{array}{c}5 \\
8 \\
14 \\
3 \\
\end{array}$ & $\begin{array}{l}16.7 \\
26.7 \\
46.7 \\
10.0\end{array}$ & $\begin{array}{l}9 \\
7 \\
9 \\
5\end{array}$ & $\begin{array}{l}30.0 \\
23.3 \\
30.0 \\
16.7 \\
\end{array}$ \\
\hline $\begin{array}{cl}\text { Occupation: } \\
\bullet & \text { Office work } \\
\text { - } & \text { Machinery work } \\
\bullet & \text { Farmer } \\
\text { - } & \text { House wife }\end{array}$ & $\begin{array}{c}5 \\
7 \\
18 \\
0\end{array}$ & $\begin{array}{c}16.7 \\
23.3 \\
60.0 \\
0.0\end{array}$ & $\begin{array}{c}4 \\
1 \\
0 \\
25\end{array}$ & $\begin{array}{c}13.3 \\
3.3 \\
0.0 \\
83.3\end{array}$ & $\begin{array}{c}7 \\
8 \\
15 \\
0\end{array}$ & $\begin{array}{c}23.3 \\
26.7 \\
50.0 \\
0.0\end{array}$ & $\begin{array}{c}7 \\
1 \\
0 \\
22\end{array}$ & $\begin{array}{c}23.3 \\
3.3 \\
0.0 \\
73.3\end{array}$ \\
\hline
\end{tabular}

Table (2): Frequency distribution of the study sample according to risk factors and associated disease:

\begin{tabular}{|c|c|c|c|c|c|c|c|c|}
\hline \multirow{3}{*}{ Variables } & \multicolumn{4}{|c|}{ Foley catheters } & \multicolumn{4}{|c|}{ Silicon catheters } \\
\hline & \multicolumn{2}{|c|}{$\begin{array}{c}\text { Male } \\
\text { No. }=\mathbf{3 0}\end{array}$} & \multicolumn{2}{|c|}{$\begin{array}{l}\text { Female } \\
\text { No.=30 }\end{array}$} & \multicolumn{2}{|c|}{$\begin{array}{c}\text { Male } \\
\text { No.=30 }\end{array}$} & \multicolumn{2}{|c|}{$\begin{array}{l}\text { Female } \\
\text { No.=30 }\end{array}$} \\
\hline & NO. & $\%$ & NO. & $\%$ & NO. & $\%$ & NO. & $\%$ \\
\hline $\begin{array}{c}\text { Length of stay: } \\
\qquad 1-3 \quad \text { days }\end{array}$ & 0 & 0.0 & 0 & 0.0 & 0 & 0.0 & 0 & 0.0 \\
\hline - $4-6$ days & 2 & 6.7 & 15 & 50.0 & 9 & 30.0 & 5 & 16.7 \\
\hline - $7-9$ days & 14 & 46.7 & 13 & 43.3 & 9 & 30.0 & 13 & 43.3 \\
\hline - $10-12$ days & 14 & 46.7 & 2 & 6.7 & 12 & 40.0 & 12 & 40.0 \\
\hline $\begin{array}{l}\text { Chronic illness: } \\
\bullet \quad \text { Hypertension }\end{array}$ & 8 & 26.7 & 12 & 40.0 & 7 & 23.3 & 8 & 26.7 \\
\hline - $\quad$ Cardiac vascular disease & 5 & 16.7 & 6 & 20.0 & 5 & 16.7 & 5 & 16.7 \\
\hline - $\quad$ Pulmonary disease & 3 & 10.0 & 4 & 13.3 & 4 & 13.3 & 6 & 20.0 \\
\hline - $\quad$ Kidney disease & 4 & 13.3 & 1 & 3.3 & 6 & 20.0 & 4 & 13.3 \\
\hline - $\quad$ Endocrine disease & 1 & 3.3 & 1 & 3.3 & 3 & 10.0 & 0 & 0.0 \\
\hline - $\quad$ None & 9 & 30.0 & 6 & 20.0 & 5 & 16.7 & 7 & 23.3 \\
\hline
\end{tabular}




\begin{tabular}{|c|c|c|c|c|c|c|c|c|}
\hline \multirow{3}{*}{ Variables } & \multicolumn{4}{|c|}{ Foley catheters } & \multicolumn{4}{|c|}{ Silicon catheters } \\
\hline & \multicolumn{2}{|c|}{$\begin{array}{c}\text { Male } \\
\text { No. }=30\end{array}$} & \multicolumn{2}{|c|}{$\begin{array}{l}\text { Female } \\
\text { No.=30 }\end{array}$} & \multicolumn{2}{|c|}{$\begin{array}{c}\text { Male } \\
\text { No. }=30\end{array}$} & \multicolumn{2}{|c|}{$\begin{array}{l}\text { Female } \\
\text { No. }=30\end{array}$} \\
\hline & NO. & $\%$ & NO. & $\%$ & NO. & $\%$ & NO. & $\%$ \\
\hline $\begin{array}{c}\text { Risk factors for infection: } \\
\text { - Female gender }\end{array}$ & 0 & 0.0 & 25 & 83.3 & 0 & 0.0 & 24 & 80.0 \\
\hline - $\quad$ Previous urinary infection & 3 & 10.0 & 2 & 6.7 & 1 & 3.3 & 5 & 16.7 \\
\hline - $\quad$ Kidney stones & 0 & 0.0 & 0 & 0.0 & 1 & 3.3 & 0 & 0.0 \\
\hline - $\quad$ Smoking & 15 & 50.0 & 0 & 0.0 & 17 & 56.7 & 0 & 0.0 \\
\hline - $\quad$ Abnormal creatinine level & 1 & 3.3 & 0 & 0.0 & 1 & 3.3 & 0 & 0.0 \\
\hline - $\quad$ Urine bag above bladder level & 5 & 16.7 & 2 & 6.7 & 1 & 3.3 & 0 & 0.0 \\
\hline - Inadequate fluid intake & 6 & 20.0 & 1 & 3.3 & 9 & 30.0 & 1 & 3.3 \\
\hline
\end{tabular}

Table (3): Frequency distribution of the study sample according to laboratory investigation:

\begin{tabular}{|c|c|c|c|c|c|c|c|c|}
\hline \multirow{3}{*}{ Variables } & \multicolumn{4}{|c|}{ Foley catheters } & \multicolumn{4}{|c|}{ Silicon catheters } \\
\hline & \multicolumn{2}{|c|}{$\begin{array}{c}\text { Male } \\
\text { No. }=\mathbf{3 0}\end{array}$} & \multicolumn{2}{|c|}{$\begin{array}{l}\text { Female } \\
\text { No.=30 }\end{array}$} & \multicolumn{2}{|c|}{$\begin{array}{c}\text { Male } \\
\text { No. }=30\end{array}$} & \multicolumn{2}{|c|}{$\begin{array}{l}\text { Female } \\
\text { No. }=30\end{array}$} \\
\hline & NO. & $\%$ & NO. & $\%$ & NO. & $\%$ & NO. & $\%$ \\
\hline $\begin{array}{c}\text { Urine culture: } \\
\qquad \quad \text { Negative } \\
\bullet \quad \text { Positive }\end{array}$ & $\begin{array}{l}10 \\
20\end{array}$ & $\begin{array}{l}33.3 \\
66.7\end{array}$ & $\begin{array}{c}7 \\
23\end{array}$ & $\begin{array}{l}23.3 \\
76.7\end{array}$ & $\begin{array}{l}17 \\
13\end{array}$ & $\begin{array}{l}56.7 \\
43.3\end{array}$ & $\begin{array}{l}12 \\
18\end{array}$ & $\begin{array}{l}40.0 \\
60.0\end{array}$ \\
\hline
\end{tabular}

Table (4): Frequency distribution of the study sample according to local infection manifestations:

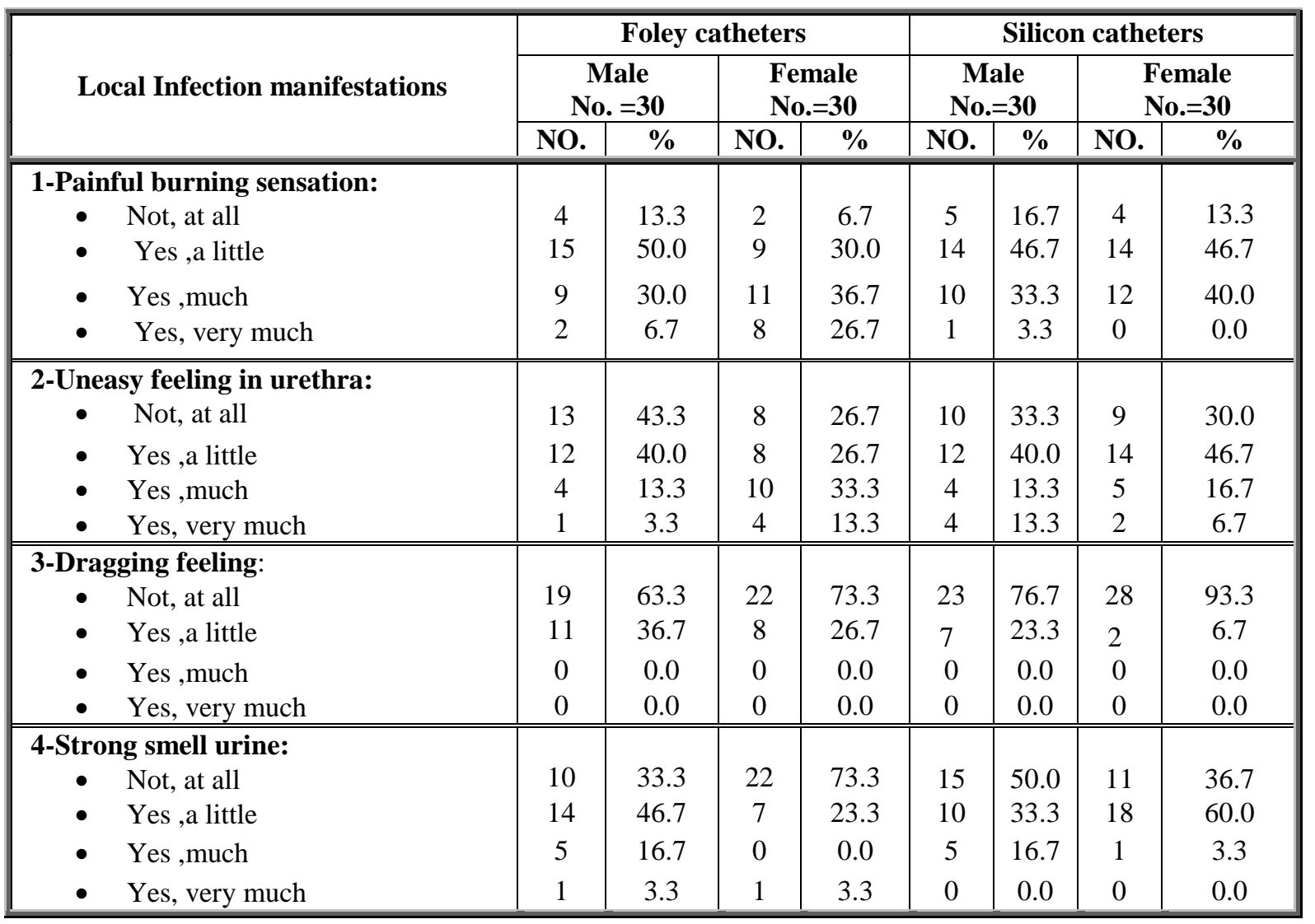


Table (5): Frequency distribution of the study sample according to general infection manifestations:

\begin{tabular}{|c|c|c|c|c|c|c|c|c|}
\hline \multirow{3}{*}{ General infection manifestations } & \multicolumn{4}{|c|}{ Foley catheters } & \multicolumn{4}{|c|}{ Silicon catheters } \\
\hline & \multicolumn{2}{|c|}{$\begin{array}{c}\text { Male } \\
\text { No. }=\mathbf{3 0}\end{array}$} & \multicolumn{2}{|c|}{$\begin{array}{l}\text { Female } \\
\text { No. }=30\end{array}$} & \multicolumn{2}{|c|}{$\begin{array}{c}\text { Male } \\
\text { No. }=30\end{array}$} & \multicolumn{2}{|c|}{$\begin{array}{l}\text { Female } \\
\text { No.=30 }\end{array}$} \\
\hline & NO. & $\%$ & NO. & $\%$ & NO. & $\%$ & NO. & $\%$ \\
\hline 1-Fever & & & & & & & & \\
\hline Not, at all & 3 & 10.0 & 1 & 3.3 & 2 & 6.7 & 0 & 0.0 \\
\hline Yes ,a little & 8 & 26.7 & 9 & 30.0 & 14 & 46.7 & 3 & 10.0 \\
\hline Yes ,much & 10 & 33.3 & 9 & 30.0 & 9 & 30.0 & 15 & 50.0 \\
\hline Yes, very much & 9 & 30.0 & 11 & 36.6 & 5 & 16.7 & 12 & 40.0 \\
\hline $\begin{array}{l}\text { 2-Confusion: } \\
\text { Not, at all }\end{array}$ & 30 & 100.0 & 30 & 100.0 & 28 & 93.3 & 30 & 100.0 \\
\hline Yes ,a little & 0 & 0.0 & 0 & 0.0 & 2 & 6.7 & 0 & 0.0 \\
\hline Yes ,much & 0 & 0.0 & 0 & 0.0 & 0 & 0.0 & 0 & 0.0 \\
\hline Yes, very much & 0 & 0.0 & 0 & 0.0 & 0 & 0.0 & 0 & 0.0 \\
\hline
\end{tabular}

Table (6): Relation between incidence of urinary tract infection and catheter type, sex, length of hospital stay:

\begin{tabular}{|c|c|c|c|c|c|}
\hline \multirow{3}{*}{ Variables } & \multicolumn{4}{|c|}{ Incidence of UTI infection } & \multirow{3}{*}{ P.value } \\
\hline & \multicolumn{2}{|c|}{$\begin{array}{l}\text { Positive } \\
\text { No. }=74\end{array}$} & \multicolumn{2}{|c|}{$\begin{array}{c}\text { Negative } \\
\text { No. }=46\end{array}$} & \\
\hline & NO. & $\%$ & NO. & $\%$ & \\
\hline $\begin{array}{c}\text { Types of catheters: } \\
\text { - } \quad \text { Foley catheter } \\
\text { - } \quad \text { Silicon catheter }\end{array}$ & $\begin{array}{l}43 \\
31\end{array}$ & $\begin{array}{l}58.1 \\
419\end{array}$ & $\begin{array}{l}17 \\
29\end{array}$ & $\begin{array}{l}36.9 \\
631\end{array}$ & 0.03* \\
\hline - Silicon catheter & & & & & \\
\hline $\begin{array}{l}\text { Sex: } \\
\qquad \quad \text { Male }\end{array}$ & 33 & 44.6 & 27 & 58.7 & 0.09 n.s \\
\hline - Female & 41 & 55.4 & 19 & 41.3 & \\
\hline Length of hospital stay: & & & & & \\
\hline - 4-6 days & 11 & 14.9 & 20 & 43.5 & \\
\hline - $7-9$ days & 28 & 37.8 & 21 & 45.6 & $0.001 * *$ \\
\hline - $10-12$ days & 35 & 47.3 & 5 & 10.9 & \\
\hline
\end{tabular}

Table (7): Relation between incidence of urinary tract infection and risk factors:

\begin{tabular}{|c|c|c|c|c|c|}
\hline \multirow{3}{*}{ Variables } & \multicolumn{4}{|c|}{ Incidence of UTI infection } & \multirow{3}{*}{ P.value } \\
\hline & \multicolumn{2}{|c|}{$\begin{array}{l}\text { Positive } \\
\text { No. }=74\end{array}$} & \multicolumn{2}{|c|}{$\begin{array}{l}\text { Negative } \\
\text { No. }=46\end{array}$} & \\
\hline & NO. & $\%$ & NO. & $\%$ & \\
\hline $\begin{array}{l}\text { Chronic illness: } \\
\bullet \quad \text { Hypertension }\end{array}$ & 24 & 32.4 & 11 & 24.0 & \multirow{6}{*}{$0.001 * *$} \\
\hline - Cardiac vascular disease & 15 & 20.3 & 6 & 13.0 & \\
\hline - $\quad$ Pulmonary disease & 14 & 18.9 & 3 & 6.5 & \\
\hline - $\quad$ Kidney disease & 13 & 17.6 & 2 & 4.3 & \\
\hline - Endocrine disease & 3 & 4.1 & 2 & 4.3 & \\
\hline - $\quad$ None & 5 & 6.7 & 22 & 47.9 & \\
\hline $\begin{array}{rr}\text { Risk factors for infection: } \\
\bullet \quad \text { Female gender }\end{array}$ & 30 & 40.5 & 19 & 41.3 & \\
\hline - $\quad$ Previous urinary infection & 11 & 14.9 & 0 & 0.0 & \\
\hline
\end{tabular}




\begin{tabular}{|c|c|c|c|c|c|c|}
\hline & \multirow{3}{*}{ Variables } & \multicolumn{4}{|c|}{ Incidence of UTI infection } & \multirow{3}{*}{ P.value } \\
\hline & & \multicolumn{2}{|c|}{$\begin{array}{l}\text { Positive } \\
\text { No. }=74\end{array}$} & \multicolumn{2}{|c|}{$\begin{array}{c}\text { Negative } \\
\text { No. }=46\end{array}$} & \\
\hline & & NO. & $\%$ & NO. & $\%$ & \\
\hline - & Kidney stones & 0 & 0.0 & 1 & 2.2 & \multirow[t]{5}{*}{$0.001 * *$} \\
\hline$\bullet$ & Smoking & 19 & 25.7 & 13 & 28.3 & \\
\hline$\bullet$ & Abnormal creatinine level & 2 & 2.8 & 0 & 0.0 & \\
\hline$\bullet$ & Urine bag above bladder level & 5 & 6.7 & 3 & 6.5 & \\
\hline$\bullet$ & Inadequate fluid intake & 7 & 9.4 & 10 & 21.7 & \\
\hline
\end{tabular}

Table (1):shows that, socio-demographic characteristics among the study sample; Regarding their age, it was noticed that, two third of foley and male silicon catheters patients $(60.0 \%)$ aged between 31-50 years, while in female silicon catheters age divided equally between the different age groups $(33.3 \%)$. Concerning educational level, more than half of foley and silicon catheters patients were read and write and basic education $(66.6 \%$ and $46.7 \%$ respectively). Regarding occupation, it was observed those more than three quarters of the female patients in foley and silicon catheters (83.3\%) were housewives, while in male foley and silicon catheters patients $(60.0 \%$ and $50.0 \%$ respectively ) of them were farmer. Concerning marital status, more than three quarters of two groups $(93.3 \%)$ were married; while $(3.3 \%)$ only of foley catheters patients were single.

Table (2): shows the distribution of the study sample according to risk factors and associated disease; Regarding their length of stay, it was noticed that, half of female foley catheters patients $(50.0 \%)$ admitting between 4-6 days, while less than half of foley and silicon catheters patients (46.7\% and $43.3 \%$ respectively) admitting between 7-9 days and 10-12 days. Concerning chronic illness, more than half of foley and silicon catheters patients $(66.7 \%$ and $50.0 \%$ respectively) were hypertension. Regarding risk factors for infection, more than three quarters of female patients $(83.3 \%)$ were female gender and more than half of male patients (56.7\%) were smokers.

Table (3): represented the laboratory investigation among study sample; concerning result of urine culture, reported that more than three quarters of foley catheters patients $(76.7 \%)$ were positive culture result, in the same line two third of silicon catheters patients $(60.0 \%)$ were positive culture result.

Table (4): Presents the distribution of patients regarding their local infection manifestations; half of foley catheters patients $(50.0 \%)$ reported that they yes, a little felt painful burning sensation, while less than half of silicon catheters patients $(46.7 \%$ and $40.0 \%$ respectively) reported that they yes, a little and yes, much felt Painful burning sensation. Less than half of foley catheters patients (43.3\%) not, at all felt uneasy feeling in urethra, while nearly of half of silicon catheters patients $(46.7 \%)$ yes, a little had this feeling. Half of foley catheters patients $(50.0 \%)$ reported that they yes, a little had burning sensation, while forty percent of silicon catheters patients $(40.0 \%)$ were yes, much had this feeling. Less than three quarters foley catheters patients $(73.3 \%)$ reported that they not, at all had strong smell urine, while two third of silicon catheters patients $(60.0 \%)$ reported that they yes, a little had strong smell urine.

Table (5): ill-uses that more than one third of foley catheters patients $(36.6 \%)$ reported that they yes, very much had fever, while less than half of silicon catheters patients $(46.7 \%)$ reported that they yes, a little had fever. Majority of the patients in two groups $(100.0 \%$ and $93.3 \%)$ were not, at all had confusion, while $(6.7 \%)$ of male silicon catheters patients were yes, a little had confusion.

Table (6) reveals that significant relation was noticed regarding to incidence of urinary tract infection and types of catheter. Also statistically highly significant relation was found between incidence of urinary tract infection and length of hospital stay ( $\mathrm{P}=0.001$ ), but non-significant relation between incidence of urinary tract infection and patients sex.

Table (7): Presents highly significant relation was noticed regarding to incidence of urinary tract infection and chronic illness, risk factors for infection $(\mathrm{P}=0.001)$.

\section{Discussion:}

The discussion will cover the main result findings as follow:

In the present study, findings regarding to patients' characteristics revealed that, two third of foley and male silicon catheters patients aged between 31-50 years, this finding was supported by Chung $\boldsymbol{\&}$ Chen (2012), who reported that more than one third of the total studied patients were in the age group from 30 49 years old. As well, Jason, et al (2013), mentioned that, Fifty five percent of the studied patients were in the age group from 40-54.while, this 
result disagrees with Zhong \&Zhou (2011), who reported that the more than half of the studied patients from 60-74 years.

In relation to educational level, more than half of foley and silicon catheters patients were read and write and basic education, which explains why they were not interested in catheter care, period of catheterization and follow up. On the other side highly educated patients represented less than ten percent of the sample and interested in catheter care, period of catheterization and follow up to prevent complications. This result was supported by Guzman, et al (2004), who mentioned that significant reduction in catheter-associated UTI in patients with higher education had increased awareness toward the complications and the importance of follow up routine.

As regards the work status of the studied patients, the present study results revealed that more than three quarters of the female patients were housewives, while two third of male patients were farmer, these finding may be attributed to the nature of the education level of studied patients.

The results of the present study showed that half of foley catheterized patients admitting between 4-6 days, while less than half of silicon catheterized patients admitting between 7-9 days and 10-12 days. In this respects, Manish, et al (2012), who reported that more than three quarters of patients length of stay (days) was 6.7 days. Also supported by Kathleen \& Mary (2012), in their study more than half of patients length of stay (days) was 11.5 days. This result disagrees with Tenke, et al (2008), who reported that more than half of patients length of stay (months) was 3-5 months.

As regard the presence of a chronic illness, the study revealed that more than half of foley and silicon catheters patients. This result supported by Gray (2006), in their study two third of studied patients was having hypertension and heart disease.

Concerning risk factors for infection; results revealed that, more than three quarters of patients were female gender and more than half of male patients were smokers. In the same line, a studies by Grabe, et al (2010), and Classen \&Nicolle (2009), which reported that the major risk factors for urinary tract infection increase period of catheterization, female gender and previous infection.

The result of the present study showed that, urine culture result in groups were more than three quarters of foley catheters patients were positive culture result, also in groups of silicon catheters two third of patients were positive culture result. This result show that not only type of catheter who decrease incidence of urinary tract infection but also technique of catheter insertion, age, patient habits, risk factors and post catheterization care. In the same line Seung-Ju, et al (2004), who declared that the incidence of CAUTI was seen in more than half of patients and this not only related to catheter material but also another factors as catheter care and patients age. This result disagrees with Amani, et al (2012), who reported that catheter material was major cause of CAUTI so using silicon catheter decrease incidence of infection but using foley catheter increase incidence of infection.

As regard the manifestations of urinary tract infection which is divided to local manifestations and general manifestations of infection; this study show that local manifestation such as Painful burning sensation half of the patients were yes, a little. Uneasy feeling in urethra nearly half of the patients were yes ,a little, while dragging feeling More than three quarters of the patients were not, at all, but more than three quarter of the patients reported that they not, at all had urine contains blood.

As regard the general manifestation of infection, this study show that half of the patients were yes, much had fever, but majority of the patients were not, at all had confusion. In the same line, a study by Talaat, et al (2010), who reported that about three quarters of studied cases were had fever and this of major criteria of CAUTI.

According to the catheter types and incidence of urinary tract infection the current study results revealed that, there was statistically significant relation between catheter types and incidence of urinary tract infection. This result agrees with Nacey, et al (2009), who reported that, incidence of urethritis in the patients catheterized with latex catheters was (11/50), compared with (1/50) in the patients catheterized with silicone catheters. This difference in the incidence of urethritis is statistically significant $(\mathrm{P}<0.01)$.

Relation between presence of chronic illness and incidence of urinary tract infection has been found a highly significant relation this result Prove that presence of chronic illness increase incidence of urinary tract infection among patients. This finding supported by Smithson, et al (2012), who stated that patients with chronic diseases such as hypertension ,heart disease and others has been highly incidence of catheter associated urinary tract infection. Also supported by Curtis (2012), who reported that hypertension can make patient more susceptible to developing renal infections.

These studies show that highly significant relation between the risk factors for infection and incidence of urinary tract infection. This result agrees with Zhan, et al (2009), who reported that more than half of patients with CAUTI have one or more of risk factors for infection. 
Finally, based on the study results; significant different in incidence of catheter-associated urinary tract infection (CAUTI) between Foley and silicone catheter in patients but non- significant different in CAUTI between male and female in patients undergoing urinary catheterization in urology department, this result related to ignoring aseptic technique in catheter insertion and ignoring care of catheter.

\section{Conclusion:}

Based on findings of the present study, it can be concluded that:

Incidence rate of catheter associated urinary tract infection between foley and silicon catheter, was more than three quarters of foley's catheterized patients $(76.7 \%)$ were positive culture result while two third of silicon catheterized patients $(60.0 \%)$ were positive culture result. Statistically highly significant relation was found between incidence of urinary tract infection and patient's age. Significant relation was present between incidence of urinary tract infection and types of catheter, length of hospital.

Highly significant relation was present between incidence of urinary tract infection and period of catheterization, indication for catheterization. Highly significant relation was noticed regarding to incidence of urinary tract infection and chronic illness, risk factors for infection.

Recommendations

Based on the finding of this study, following recommendations were made:

I. For Nurses:

- Use a sterile procedure for catheter insertion to reduce catheter associated infection.

- Encourage nurses to attend seminars and workshops to enrich their knowledge of all that is modern in this area.

- Training courses for nurses about catheter insertion and care.

- Minimize duration of the catheterization because the risk of CAUTI increasing after 5-6 days of insertion.

- Maintain a closed drainage system and routine perineal care is recommended.

- Keep the collection device below the level of the bladder/tubing.

II. In services:

- Increasing alert of health care staff about infection control and measure to prevent CAUTI through work shop, posters and health education.
- Provide facilities and sterile equipments that are required in catheter insertion, infection control committee to follow work in hospital and apply standard in patients care.

- Provision of statistical center in the hospital that have a database about the incidence and magnitude of the problem.

III. For research (future study):

- Designing and application nursing care standard for catheter insertion and care.

\section{References}

1. Amani E., Tamer S.,\& Mervat G.,(2012): American Journal of Infection Control, Deviceassociated nosocomial infection rates in intensive care units at Cairo University hospitals: First step toward initiating surveillance Programs in a resource-limited country, Vol 40, No 1, PP 216220.

2. Bjerklund J., Cek M.,\& Naber K.,(2007): Journal of European Urology, Prevalence of hospital-acquired urinary tract infections in urology department, Vol 51, PP 1100 - 1112.

3. Chung Y., \& Chen H.,( Jun 2012): Journal of Biological Research For Nursing, Vinegar for Decreasing Catheter-Associated Bacteriuria in Long-Term Catheterized Patients, Vol 14, No 3, PP 294-301.

4. Classen D., \&Nicolle L., (Oct 2009): The Journal of Infection Control and Hospital Epidemiology, Strategies to Prevent CatheterAssociated Urinary Tract Infections in Acute Care Hospitals, Vol29, No 1, PP 40-43.

5. Curtis M., (2012), High blood Pressure and kidney infections; available at:

6. Dudeck M., Horan T.,\& Peterson K.,( 2011): The American Journal of Infection control, device-associated module, Vol 39, No 1, PP 349367.

7. Gould C., Umscheid C.,\& Agarwal R.,(2010): The Journal of Infection Control and Hosp Epidemiology, Guideline for prevention of catheter-associated urinary tract infections, Vol31,No 4, PP 319-326.

8. Grabe M., Botto H., \&Naber K.,(2010): The Journal of European Association of Urology, Guidelines on urological infections, Vol 54, No 3, PP 65-71.

9. Gray M.,(2006): The Journal of Wound Ostomy Continence Nurse, Does the construction material affect outcomes in long-term catheterization, Vol 33, PP 116-121.

10. Guzman S., Rosenthal v., \& Safdar N.,(2004): The Journal of Infection Control and Hospital Epidemiology, Effect of education and 
performance feedback on rates of catheterassociated urinary tract infection in intensive care units in Argentina, Vol 25, No 1, PP 47-50.

11. Hooton T., Bradley S.,\& Cardenas D.,(2010): The Journal of Clinical Infectious disease, Diagnosis, prevention, and treatment of catheterassociated urinary tract infection in adults Guidelines from the Infectious Diseases Society of America, Vol 50, No 5, PP 625-663.

12. Jason Y., Chan M. ,\& Yevgeniy R., ( January 2013): Journal of American Academy of Otolaryngology- Head and Neck Surgery, Postoperative Urinary Tract Infection and ShortTerm Outcomes and Costs in Head and Neck Cancer Surgery, Vol 10,No 2, PP 23-33.

13. Kathleen S., \& Mary B., (2012): American Journal of Infection Control, Nurse-directed interventions to reduce catheter-associated urinary tract infections, Vol 51, No 4, PP 548553.

14. Kunin C., (2006): International Journal of Antimicrobial Agents, Urinary catheter associated infections in the elderly, Vol 8, PP7881.

15. Manish M., Mary E., \& James R.,( 2012): American Journal of Infection Control, Inappropriate use of urinary catheters: A prospective observational study, Vol 51,No 4, PP 51-54.

16. Nacey J., Tulloch A., \& Ferguson F.,(2009) : British Journal of Urology, Catheter-induced urethritis: a Comparison Between Latex and Silicone Catheters in a Prospective Clinical Trial ,Vol 105, No 2, PP 325-328.

17. Schumm K.,\& Lam T.,(2009): Journal of Neurourology and Urodynamics, Types of urethral catheters for management of short-term voiding problems in hospitalized adults, Vol 27,PP 738-746.

18. Seung-Ju L., Sae W., \&Sung J.,(2004): International Journal of Antimicrobial Agents, A comparative multicentre study on the incidence of catheter-associated urinary tract infection between nitrofurazone-coated and silicone catheters, Vol 24, No 1, PP 65-69.

19. Smithson A., Chico C., \&Ramos J.,(2012): Europe Journal of Clinical Microbiology Infectious Disease, Prevalence and risk factors for quinolone resistance among Escherichia coli strains isolated from males with community febrile urinary tract infection, Vol 31, No 1, PP 423-430.

20. Stenzelius K., Persson S., Olsson U.,\& Stjarneblad M., (2011): Scandinavian journal of urology and nephrology, Nobel metal alloycoated latex versus silicon foley catheter in short term catheterization:a randomized controlled study, Vol 45, No 4, PP 258-264.

21. Talaat M., Hafez S., \&Saied T.,(2010): American Journal of Infection Control, Surveillance of catheter-associated urinary tract infection in 4 intensive care units at Alexandria university hospitals in Egypt, Vol 38, No 8, PP 222-224.

22. Tenke P., Kovacs B.,\& Matsumoto T., (2008): International Journal of Antimicrobial Agents, European and Asian guidelines on management and prevention of catheter-associated urinary tract infections, Vol 31, PP 68-78.

23. Thomas M., Suzanne F.,\& Diana D.,(2010): Journal of Clinical Infectious Diseases, Diagnosis, prevention, and Treatment of Catheter Associated Urinary Tract Infection in Adults ,Vol 50, PP 625-663.

24. Zhan D., Elixhauser A., \&Richards CL., (2009): The Journal of Medical Care, Identification of hospital-acquired catheterassociated urinary tract infections, Vol 47, No 3, PP 364 - 369.

25. Zhong Y., \&Zhou J., ,(Dec 2011): The Journal of International Medical Research, Effectiveness and Safety of patient-Initiated Single-Dose versus Continuous Low-Dose Antibiotic prophylaxis for Recurrent Urinary Tract Infections, Vol 39,No 6, PP 335 - 343. 